This paper is the final draft post-refereeing of the following article:

Mohsenzadeh V, Wiebe L. 2018. Effect of beam-column connection fixity and gravity framing on the seismic collapse risk of special concentrically braced frames. Soil Dynamics and Earthquake Engineering (Special Issue on Seismic Design and Assessment of Steel Structures), 115: 685-697.

This material may be found at DOI 10.1016/ j.soildyn.2018.09.035.

This version is posted in accordance with the copyright restrictions of Elsevier, as described at: http://sherpa.ac.uk/romeo/issn/0267-7261/ 


\title{
Effect of beam-column connection fixity and gravity framing on the seismic collapse risk of special concentrically braced frames
}

\author{
Vahid Mohsenzadeh and Lydell Wiebe
}

Department of Civil Engineering, McMaster University, Hamilton, ON, Canada

\begin{abstract}
In concentrically braced frames (CBFs), braces are typically connected at beam-column connections through gusset plates, which also increase the rotational stiffness and moment capacity of the beam-column connection. This fixity provides a reserve lateral force resisting capacity that may improve the seismic collapse capacity of the system, but that is not considered in design. Recently, a new brace connection type has been proposed that does not include a gusset plate that would stiffen and strengthen the beam-column connection. To address the implications of the range of possible connection design alternatives, this paper assesses the effects of the fixity of beam-column connections on the behaviour of three special concentrically braced frames of different heights. The results show that flexural strength and stiffness at the beam-column connections reduces the collapse probability when the gravity framing contribution is ignored, but this influence is minor for low-rise buildings and is typically much less significant than the influence of the gravity framing's stiffness and strength. Simple design recommendations are presented regarding the beam-column connection fixity within the braced bay.
\end{abstract}

KEY WORDS: earthquake engineering; steel structures; special concentrically braced frames; seismic collapse risk; nonlinear time history analysis; connection fixity; gravity framing; multiple stripe analysis

\section{Introduction}

\subsection{Motivation}

Steel special concentrically braced frames (SCBFs) are commonly used as lateral force resisting systems in regions of high seismicity. During moderate to severe earthquakes, the braces are intended to experience inelastic deformation through buckling, post-buckling and tensile yielding. Through this nonlinear behaviour of braces, energy is dissipated and the peak seismic force is limited. In current practice, a gusset plate is used to join the brace to the frame members, and brace rotation due to out-of-plane buckling is accommodated using geometrical limits (linear or elliptical clearance) on the gusset plate (Fig. 1 (a,b)) [1,2,3]. The associated out-of-plane buckling displacement can be larger than $400 \mathrm{~mm}$ before the brace fractures [4], causing damage to adjacent infill walls or cladding. To reduce toe weld fractures at the gusset plate and avoid damage due to out-of-plane deformation, an alternative detail has been proposed that uses a knife plate perpendicular to the gusset plate (Fig. 1(c))[5]. More recently, an alternative connection has been developed based on a replaceable brace module (Fig. 1(d)) [6]. This connection is intended to improve the constructability of braced frames by allowing bolts to be used instead of field welding, and to make the brace unit more easily replaceable by confining all damage to the replaceable brace module. An experimental study by Stevens and Wiebe [6] has shown that this proposed connection can provide comparable seismic performance (i.e. yield and failure development, drift range before brace fracture, and cumulative energy dissipated) as current SCBF connections. However, whereas the gusset plate in other connections provides an undesigned level of beam-column fixity that could affect the collapse capacity of braced frames [7], omitting the gusset plate allows the designer to select the beamcolumn connection fixity. Therefore, there is a need to determine what level of fixity, if any, is required to ensure adequate collapse capacity of an SCBF. 

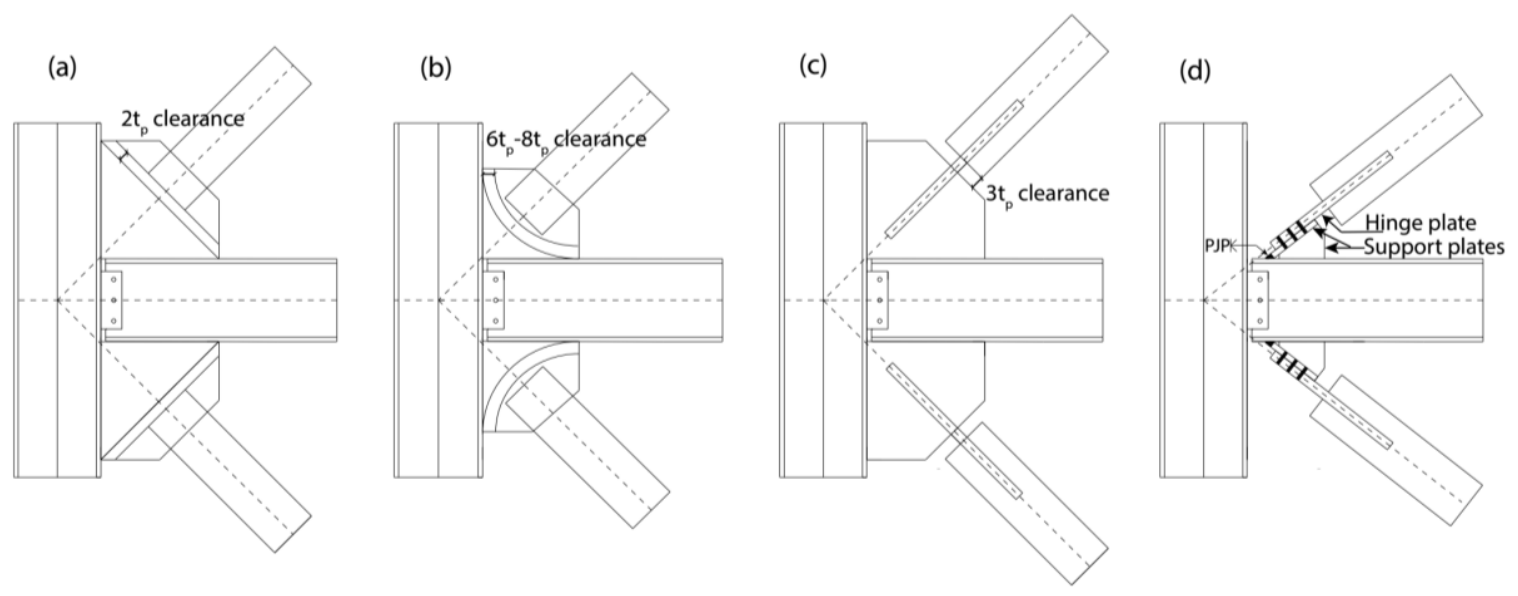

Fig 1. Brace connection details; a) Linear hinge zone b) Elliptical hinge zone c) Knife plate configured for in-plane buckling d) Proposed replacement/modular connection

\subsection{Background}

In current practice, designers often model SCBFs by assuming a pinned connection for beam-column connections with gusset plates. This is an attractive assumption as it simplifies the analysis and design process. However, it has been shown that the gusset plate can increase the flexural strength and stiffness of beam-column connections [8][9] enough to develop substantial frame action through bending of beams and columns [5]. Results of an experimental study on a full scale single braced bay by Lehman et al. [2] showed that the gusset plate in an SCBF can induce considerable inelastic deformations into adjacent beams and columns because of bending moments coming from the frame action. Uriz and Mahin [10] investigated the cyclic behaviour of braced frame beam-column connections in a full scale two-storey SCBF test. Conventional detailing requirements (Fig. 1(a)) were used to join the gusset plate to the frame members. After the first-storey braces fractured, the beam and column framing could still develop about $30 \%$ of the peak lateral resistance. This reserve capacity can also improve the collapse capacity of CBFs designed for moderate seismicity, becoming especially important after the braces fracture [11][12][13]. Kanyilmaz [13] investigated the effects of frame action on the global performance of CBF systems that were designed for moderate seismicity. A considerable improvement in the resistance and ductility capacity was observed in those systems where gusset plates were used to connect the brace to the frame elements relative to the frame with ideally pinned connections.

Outside of braced bays, shear-tab connections are frequently used to join beams to columns in gravity frames. These connections are typically idealized as pinned in design because of their low contribution to the initial stiffness and base shear [14]. However, these connections can provide up to $20 \%$ of the plastic flexural capacity (Mp) of the beam in a bare steel frame, and up to 50\% of Mp in the presence of the slab [15][16]. Due to the number of shear-tab connections in a building, their collective role may be significant [17]. Moreover, gravity columns can also reduce the drift concentration by providing lateral strength and stiffness that improve the seismic performance after brace fracture [18] [19]. Hsiao et al. [20] concluded that modelling gravity framing connections could reduce the drifts significantly in the case of a low-rise (three-storey) SCBF building, assuming fixed beam-column connections within the braced bay. Malaga-Chuquitaype et al. [21] reported an improvement of $40 \%$ in the median collapse intensity of a 6-storey $\mathrm{CBF}$ after considering the lateral strength and stiffness of gravity framing. More recently, another study conducted by Hwang and Lignos [22] revealed that considering the gravity framing contribution with the composite action provided by the floor slab can significantly increase the collapse capacity of SCBFs and should be considered in the collapse risk studies of SCBFs. Although FEMA P695 [23] does not recommend considering the gravity framing strength and stiffness because they are not designed as part of the seismic-force-resisting system, it does note that the methodology outlined there can be used to investigate the importance of the gravity framing, and Appendix F of that document recommends considering the gravity framing for collapse modelling. 


\subsection{Paper organization}

In light of the above discussion, this paper examines the effects of connection fixity at the beam-column connections and of gravity framing on the collapse capacity of SCBF buildings. Three different conditions (pinned, shear tab and fixed) are considered for connections within the braced bay, without and with the contributions of the gravity framing, for three archetype buildings ranging from three to 12 storeys. After examining a representative example of the modelled behaviour of one frame near the collapse intensity, fragility curves are constructed and the collapse capacity is assessed using the FEMA P695 methodology and simplified design recommendations are presented. The influence of the damping model is also investigated by using the initial stiffness rather than the tangent stiffness to define the damping for one model of each archetype building. Finally, the inter-storey drift response is investigated near the median collapse intensity, so as to highlight the effects of the connection fixity and gravity framing on the collapse mechanism of each frame.

\section{Details of archetype buildings}

To represent a range of buildings with potential differences in the importance of force redistribution after brace buckling, three archetype SCBF buildings with heights of three, six and 12 storeys are considered in this study. The buildings were designed by others for a previous study [24] and use a two-storey X-braced configuration. The buildings have a rectangular plan configuration with six $9.14 \mathrm{~m}$ bays in one direction and four $9.14 \mathrm{~m}$ bays in the other direction, as shown in Fig. 2, with a constant storey height of $4.57 \mathrm{~m}$. The seismic weight of each floor and roof is $8800 \mathrm{kN}$ and $6800 \mathrm{kN}$, respectively. Table 1 shows the seismic design parameters. The three- and six-storey buildings were designed using the equivalent lateral force (ELF) procedure, while the 12-storey building was designed according to response spectrum analysis (RSA) procedure in compliance with ASCE/SEI 7-05 [25]. The storey drift was limited to $2.5 \%$ for the three-storey building and $2.0 \%$ for the six- and 12-storey buildings. The braces are circular hollow structural sections (HSS) that satisfy the global and local slenderness ratio limits specified in ANSI/AISC 341-05 [26]. The beams were assumed to be continuously laterally supported, and a fixed-base condition was assumed for the columns, which resist lateral load through strong axis-bending. Table 2 shows the structural sections used for the considered buildings.

(a)

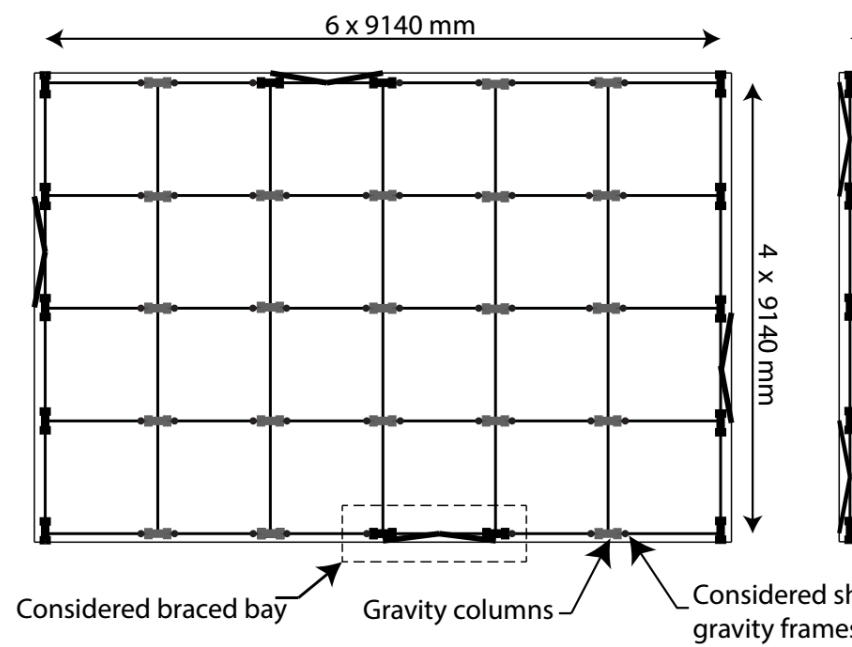

(b)

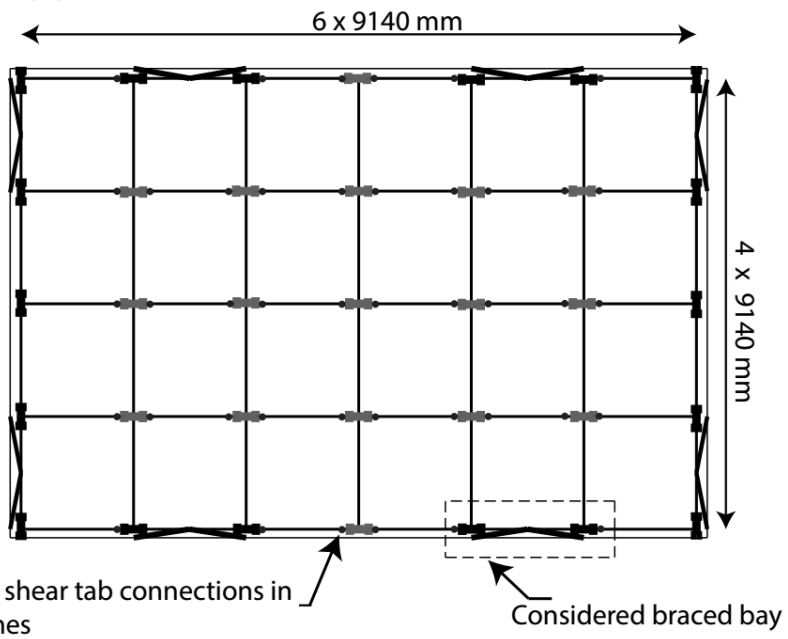

Fig. 2. a) Plan configuration of three- and six-storey buildings b) Plan configuration of 12-storey building 
Table 1

Seismic design parameters

\begin{tabular}{cc}
\hline Parameters & Value \\
\hline Importance factor & 1 \\
Site class & $\mathrm{D}$ \\
Short-period site coefficient $\left(\mathrm{F}_{\mathrm{a}}\right)$ & 1 \\
Long-period site coefficient $\left(\mathrm{F}_{\mathrm{v}}\right)$ & 1.5 \\
Design spectral acceleration at short periods $\left(\mathrm{S}_{\mathbf{D s}}\right)$ & $1.0 \mathrm{~g}$ \\
Design spectral acceleration at 1-second period $\left(\mathrm{S}_{\mathbf{D} 1}\right)$ & $0.6 \mathrm{~g}$ \\
Seismic design category & $\mathrm{D}$ \\
Response modification factor $(\mathrm{R})$ & 6.0 \\
System over-strength factor $(\Omega)$ & 2.0 \\
Deflection amplification factor $\left(\mathrm{C}_{\mathrm{d}}\right)$ & 6.0 \\
\hline
\end{tabular}

Table 2

Section sizes for SCBF

\begin{tabular}{|c|c|c|c|c|c|c|}
\hline Storey & Braces & Beams & Columns & $\begin{array}{c}\text { Gravity } \\
\text { Beams }\end{array}$ & $\begin{array}{c}\text { Gravity } \\
\text { Columns }\end{array}$ & $\alpha$ \\
\hline \multicolumn{7}{|l|}{3 -storey } \\
\hline 3 & HSS $8.75 \times 0.312$ & W30x173 & $\mathrm{W} 12 \times 120$ & W24x55 & W14x90 & 0.029 \\
\hline 2 & HSS $8.75 \times 0.5$ & W21x111 & $\mathrm{W} 12 \times 120$ & W24x55 & W14x90 & 0.019 \\
\hline 1 & HSS9.625x0.5 & W18x65 & $\mathrm{W} 12 \times 120$ & W24x55 & W14x90 & 0.017 \\
\hline \multicolumn{7}{|l|}{ 6-storey } \\
\hline 6 & HSS7.5x0.312 & W18x97 & W14x68 & W24x55 & W14x48 & 0.034 \\
\hline 5 & HSS9.625 $\times 0.375$ & W24x104 & W14x68 & W24x55 & W14x48 & 0.017 \\
\hline 4 & HSS9.625x0.5 & W24x131 & W14x176 & W24x55 & W14x74 & 0.027 \\
\hline 3 & HSS $11.25 \times 0.5$ & W18x76 & W14x176 & W24x55 & W14x74 & 0.024 \\
\hline 2 & HSS $12.5 \times 0.5$ & W24x146 & $\mathrm{W} 14 \times 342$ & W24x55 & W14x90 & 0.026 \\
\hline 1 & HSS $12.5 \times 0.5$ & W21x62 & W14x342 & W24x55 & W14x90 & 0.026 \\
\hline \multicolumn{7}{|l|}{12 -storey } \\
\hline 12 & HSS6.625x0.312 & W18x55 & W12x45 & W24x55 & W14x48 & 0.015 \\
\hline 11 & HSS6.625x0.312 & W18x35 & W12x45 & W24x55 & W14x48 & 0.015 \\
\hline 10 & HSS8.75x0.312 & W18x60 & W14x99 & W24x55 & W14x74 & 0.019 \\
\hline 9 & HSS $8.75 \times 0.312$ & W18x35 & W14x99 & W24x55 & W14x74 & 0.019 \\
\hline 8 & HSS10x0.375 & W18x65 & W14x193 & W24x55 & W14x90 & 0.018 \\
\hline 7 & HSS $10 \times 0.375$ & W18x35 & W14x193 & W24x55 & $\mathrm{W} 14 \times 90$ & 0.018 \\
\hline 6 & HSS10x0.375 & W18x65 & $\mathrm{W} 14 \times 283$ & W24x55 & $\mathrm{W} 14 \times 120$ & 0.024 \\
\hline 5 & HSS10x0.375 & W18x35 & $\mathrm{W} 14 \times 283$ & W24x55 & $\mathrm{W} 14 \times 120$ & 0.024 \\
\hline 4 & HSS9.625x0.5 & W18x71 & W14x398 & W24x55 & W14x145 & 0.024 \\
\hline 3 & HSS9.625x0.5 & W18x35 & W14x398 & W24x55 & W14x145 & 0.024 \\
\hline 2 & HSS9.625x0.5 & W18x71 & $\mathrm{W} 14 \times 550$ & W24x55 & W14x176 & 0.030 \\
\hline 1 & HSS9.625x0.5 & W18x35 & $\mathrm{W} 14 \times 550$ & W24x55 & W14x176 & 0.030 \\
\hline
\end{tabular}

\section{Numerical modelling}

The study frames were all modelled with a similar approach using OpenSees [27]. As an example, Fig. 3 shows a schematic of the numerical model for the six-storey archetype building. Force-based fiber beam-column elements were used to model the inelastic behaviour of the frame members, with a Gauss-Lobatto integration scheme to account for the distributed plasticity along the length of each element. Fibre beam-column elements were also used to capture the cyclic inelastic behaviour of the braces, following the recommendations of Uriz and Mahin [10]. A uniaxial Giuffre-Menegotto-Pinto steel material with isotropic strain hardening (Steel02) was assigned to each fiber. A nondeteriorating material (Steel02) was used for modeling the beams and columns because this was expected to be sufficiently accurate for the beams up to $5 \%$ inter-storey drift, which was defined as collapse for this study, as well as 
for the stocky columns, for which the deterioration of strength and stiffness is not expected to be significant at this drift level [28]. Initial out-of-straightness in the form of a sinusoidal function with an amplitude of L/500 [29] was considered, with each brace subdivided into twenty nonlinear beam-column elements. In order to capture fracture due to low-cycle fatigue, the strain history in each individual fiber was tracked according to a rainflow counting procedure [10] and zero stiffness was assigned to any fiber that exceeded the low-cycle fatigue limit recommended by Karamanci and Lignos [30].

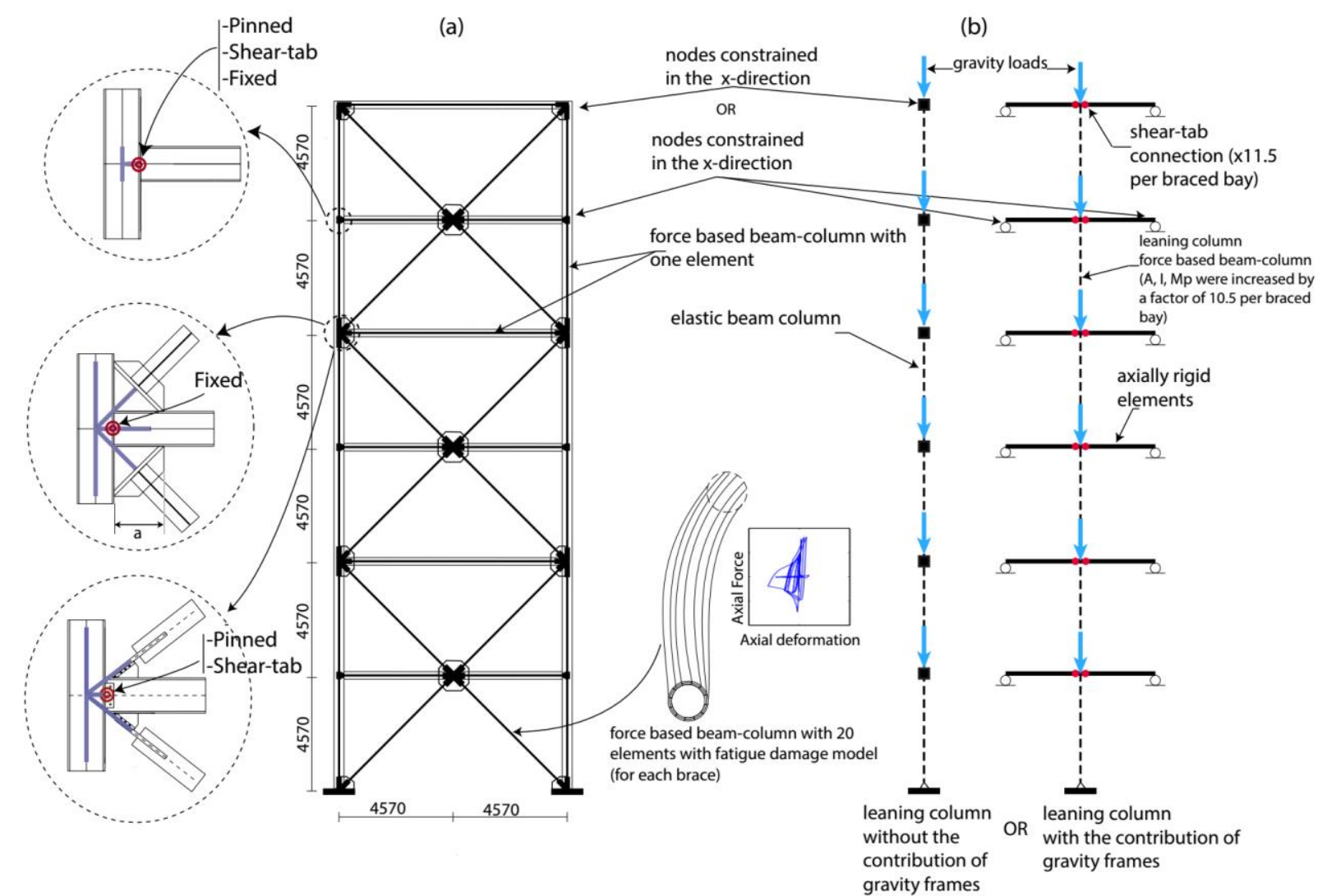

(c)

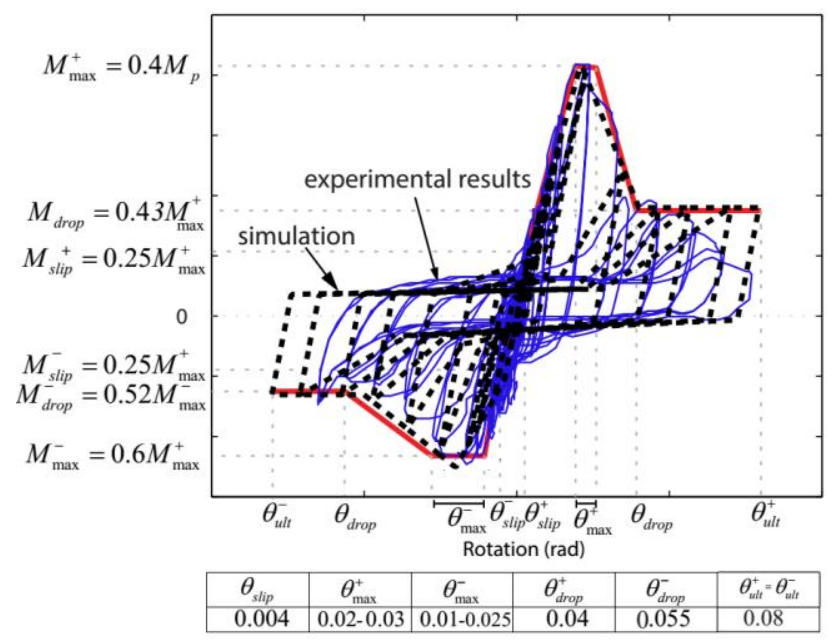

(d)

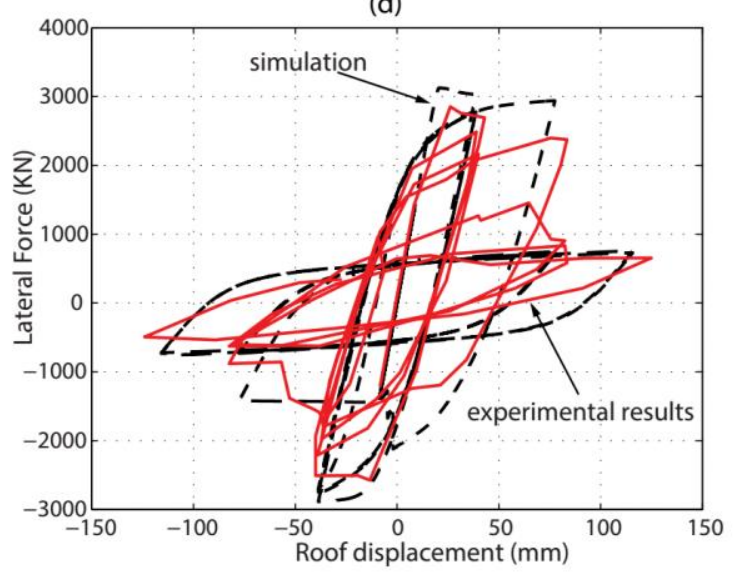

Fig. 3. a) Schematic of numerical model for six-storey SCBF. b) Leaning column without or with the simulation of lateral load resisting contribution of gravity framing. c) Composite shear-tab connection behaviour d) Global hysteretic behaviour of two-storey SCBF 
A multicomponent connection model consisting of rigid elements, fiber elements, and a nonlinear spring was used to capture the behaviour of the beam-column-gusset plate connections. The gusset plate was modelled using a fiber element with a length equal to twice the gusset plate thickness and with three integration points. Rigid offsets were modelled at the end of the elements, following the recommendations of Hsiao et al. [31]. In columns, these rigid elements extend from the work point to either the physical end of the gusset plate or the physical end of the beam, as shown in Fig. 3(a). In beams, they extend to $75 \%$ of the dimension 'a' (Fig. 3(a)).

For the nonlinear springs connecting the brace and beam elements to the column, three different assumptions were considered. First, the spring was modelled as a fixed connection as an upper bound on the strength and stiffness that the gusset plate can provide to the connection. Second, omitting the gusset plate from its current position may lead to a shear tab connection between the beam and column, as shown in Fig. 1(d). Third, as a lower bound on the possible frame contribution and because designers often assume this condition, the spring was modelled as a pin. To simulate the cyclic behaviour of shear-tab connections including strength and stiffness degradation, the Pinching4 material was employed in OpenSees. The cyclic deterioration parameters were defined as recommended by Elkady and Lignos [32], who calibrated the parameters using the test results of Liu and Astaneh [15] for a shear tab connection with a slab and the proposed moment rotation model in Liu and Astaneh [16]. Fig. 3(c) compares the hysteresis for a shear tab connection with slab from an experimental study provided in Liu and Astaneh [15] with the hysteresis loops of the shear tab spring model. Where connections were assumed to be fixed, the slab was assumed not to contribute to the response based on the assumption that the connection to the brace would prevent a slab from being attached to the beam where it could interact significantly with the connection. The panel zones were assumed to have adequate strength and stiffness that panel zone deformation could be neglected.

The modelling approach was validated against test results from a full-scale quasi-static cyclic test on two-storey braced frame with HSS braces and tapered gusset plates [10]. All beam-column connections were modelled as fixed. Fig. 3(d) compares the global hysteretic behaviour of the considered model to the experimental results. The model accurately captures the overall behaviour of the structure and cyclic performance of the frame, and strength and stiffness deterioration of the experimental results is in good agreement with the simulation results. Figure 3(d) shows that the peak resistance and the reserve lateral resistance of the model are within $10 \%$ and $13 \%$ of the experimental results, respectively.

The model contains a leaning column loaded vertically with the tributary seismic load of each floor and constrained to one braced bay node in the horizontal direction. The braced bay beams were verified to have sufficient strength and stiffness that the results were essentially the same as if a rigid diaphragm had been modelled. The P-Delta geometric transformation formulation was used to simulate $P-\Delta$ effects. When the gravity framing was to be excluded from the model, elastic beam-column elements were used to model the leaning column, no lateral stiffness was assigned to these elements, and the mass tributary to the gravity columns was lumped at the column nodes, as shown in Fig. 3(b). When the lateral load resisting contribution of gravity framing was to be included, one leaning column was used to represent all the gravity columns within the tributary area. In this case, the leaning column was modelled using forcebased fiber beam-column elements. Only the gravity columns that are oriented to bend about their strong axis were considered, so the area, moment of inertia and plastic moment capacity of one column were multiplied by a factor of 10.5 for the three- and six-storey archetype buildings, and by a factor of 4.25 for the 12 -storey building. The analyses were run with and without shear tab connections in the gravity framing to examine the individual influence of both the gravity columns and gravity framing connections on collapse capacity of SCBFs. When gravity framing connections were included, axially rigid beams with the total flexural stiffness of all gravity beams located within the tributary area on both sides of the leaning column were used to model the gravity connections. To account for all the shear tab connections within the tributary area of the gravity framing, the strength and stiffness of one shear tab connection were increased by a factor of 11.5 for three- and six-storey archetype buildings, and by a factor of 5.25 for the 12-storey building. In all cases, the base of the leaning column was modelled as pinned. Table 3 shows the fundamental periods for all considered models. By modelling beam-column connection as fixed (similar to NIST [24] assumptions), the corresponding fundamental periods are $\boldsymbol{T}_{1}=0.58 \mathrm{~s}, 1.09 \mathrm{~s}$ and $1.93 \mathrm{~s}$ for three-, six- and 12-storey buildings, respectively. These periods are within 3\% of the periods presented for the same structures in NIST [24]. The fundamental periods indicate that the influence of connection fixity and gravity framing is negligible in the elastic 
range for the considered buildings because of the large initial stiffness provided by the braces. This implies a negligible variation of the design base shear regardless of the stiffness associated with connections and gravity framing.

Table 3

Fundamental periods for models with different modeling assumptions

\begin{tabular}{|c|c|c|c|c|c|c|c|c|c|}
\hline \multirow{2}{*}{ Building Height } & \multicolumn{3}{|c|}{ Without Gravity Framing } & \multicolumn{3}{|c|}{ With Gravity Columns } & \multicolumn{3}{|c|}{$\begin{array}{c}\text { With Gravity Framing Columns } \\
\text { and Connections }\end{array}$} \\
\hline & Pinned & $\begin{array}{c}\text { Shear } \\
\text { tab }\end{array}$ & Fixed & Pinned & Shear tab & Fixed & Pinned & Shear tab & Fixed \\
\hline 3 storeys & 0.581 & 0.579 & 0.576 & 0.581 & 0.579 & 0.576 & 0.557 & 0.556 & 0.553 \\
\hline 6 storeys & 1.104 & 1.100 & 1.087 & 1.100 & 1.099 & 1.080 & 1.047 & 1.047 & 1.046 \\
\hline 12 storeys & 1.957 & 1.954 & 1.930 & 1.956 & 1.953 & 1.930 & 1.903 & 1.900 & 1.897 \\
\hline
\end{tabular}

Tangent stiffness-proportional Rayleigh damping based on 3\% of critical damping in the first and third modes was applied using the committed stiffness matrix, as Rayleigh damping using the initial stiffness can overestimate the collapse capacity of SCBFs when it is assigned to the brace elements that exhibit nonlinear behaviour [30]. The eigenvalue analysis was performed and the Rayleigh damping coefficients were recomputed for each integration step during the response history. When the eigenvalues of the first three modes were positive, damping was calculated based on both mass- and stiffness- proportional damping parts of the Rayleigh damping matrix, but when one of the eigenvalues in the first three modes became negative, the stiffness proportional damping part of the Rayleigh damping was omitted to avoid negative damping forces.

\section{Ground motion selection and scaling}

Multiple stripe analysis (MSA) [33] was conducted for the archetype buildings using the set of 44 far-field ground motions that were summarized in FEMA P695 [23]. In this method, all the ground motions are scaled to specific intensity measures (IMs), and nonlinear time history analyses are run for each intensity level. Fragility curves are constructed based on the proportion of ground motions that cause collapse at each IM level using the maximum likelihood statistical approach.

For all considered buildings, seven stripes were considered. For the three- and six-storey buildings, the ground motions were scaled using a multi-period scaling method described by Hsiao et al. [20]. According to this scaling method, ground motions are scaled to match the target spectrum before and after brace fracture. For those stripes with intensity equal to or lower than the DBE (design basis earthquake), each ground motion was scaled to meet the target spectrum using only the fundamental period based on models without gravity framing $\left(T_{1}\right)$ because brace fracture is not expected at this level. For the three- and six-storey buildings at stripes larger than the DBE, the ground motions were scaled to match the target spectrum at three different periods: the fundamental period ( $T_{1}$ ), the period of the structure with one brace removed at the first storey to simulate fracture $\left(T_{b}\right)$ and the period of the structure with both braces removed at the first storey ( $T_{c}$ ), as described by Equation 1 [20].

$$
S F=\frac{S a_{1, t}}{S a_{1, g}} w_{1}+\frac{S a_{\mathrm{b}, t}}{S a_{\mathrm{b}, \mathrm{g}}} w_{b}+\frac{S a_{\mathrm{c}, t}}{S a_{\mathrm{c}, \mathrm{g}}} w_{c}
$$

where $S a_{i, t}$ is the target elastic spectral acceleration value corresponding to each period $T_{i}$ and $S a_{i, g}$ is the spectral acceleration value of the ground motion at period $T_{i}, w_{i}$ is the weight for each period $T_{i}$. The following weights were used for this scaling method: $w_{1}=0.55, w_{b}=0.35, w_{c}=0.1$ [20]. For the 12-storey building, the modified scaling 
approach that was used by Hsiao et al. [20] for a high-rise building (20 storeys) was considered, but did not produce an acceptable match between the mean and target spectra. For that reason, the geometric-mean scaling method was used instead to scale the ground motions over a broad range of periods $\left(0.2 T_{1}\right.$ to $\left.1.5 T_{1}\right)$, following ASCE recommendations [25]. Fig. 4 shows the 5\% damped mean spectra for all considered stripes for all buildings. The mean spectra are very close to the code spectra at the DBE and MCE (maximum considered earthquake) levels at the anchor periods for the three- and six-storey buildings, and at the first- and second- mode periods for the 12-storey building. All the mean spectra overshoot the target spectra at periods shorter than $T_{s}=0.5 \mathrm{~s}$.

(a)

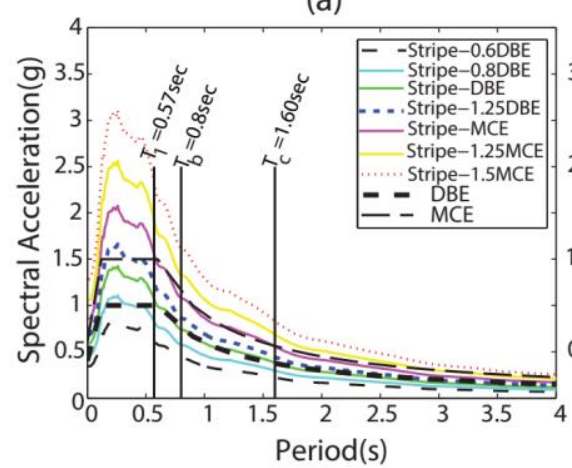

(b)

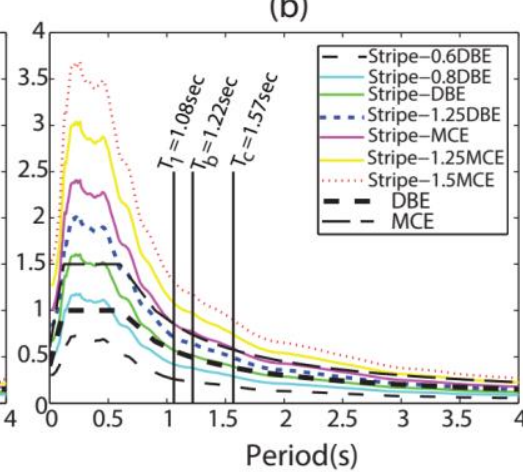

(c)

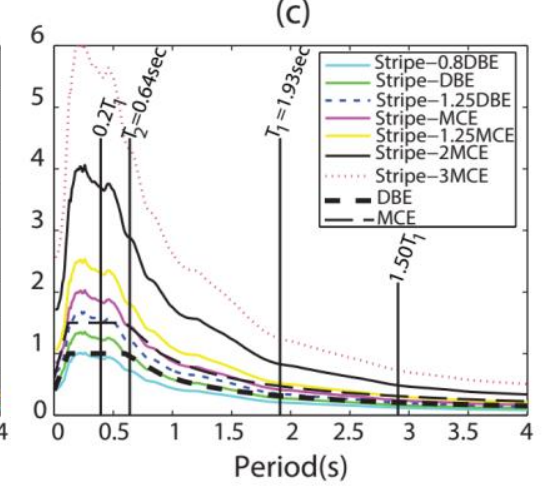

Fig. 4. Scaled mean 5\%-damped spectra for considered stripes, compared with DBE and MCE code-based spectra, for a)3-storey b)6-storey c)12-storey building

\section{Example near-collapse response of six-storey building}

In order to understand how the beam-column connection fixity and the gravity framing affect the behaviour of the braced frame systems, a representative example of the 6-storey SCBF near collapse is presented first. This section uses the results from component 2 of the Nishi-Akashi Station of the 1995 Kobe record (Table A-4C in FEMA P695 [23]) at an intensity that represents 1.25MCE (Scale Factor=3.8). Structural collapse was defined as a state at which the maximum storey drift reaches 5\% [20]. Fig. 5 shows the inter-storey drift response for the three considered models of the beam-column connections, without and with the contribution of the gravity framing. Fig. 6 presents the peak inter-storey drift ratios and sequence of damage for the same models.

\subsection{Models without gravity framing}

The storey drift response histories of the models without gravity framing and with either pinned or shear tab connections are nearly identical, as both develop the same collapse mechanism. In these two models, at $6.5 \mathrm{~s}$ the left brace in the second storey fractures, followed quickly by flexural yielding at the base of the first-storey columns, leading to collapse of the system. This demonstrates that in models with pinned or shear tab connections where the gravity framing is neglected, even a single brace fracture can trigger structural collapse.

Conversely, when the connection condition is modelled as fixed, the same model does not collapse, although the drift demand in the first three storeys still exceeds $2 \%$. The sequence of inelastic events is identified with circled numbers in Figures 5(c) and 6(c). The frame action participation delays the first brace fracture, and also allows yielding to occur in multiple locations in both beams and columns (steps 4 and 5) before a second brace fractures at $12.0 \mathrm{~s}$. This illustrates how frame action within the braced bay prevents the concentration of inelastic deformation in a single storey, thereby preventing collapse. 

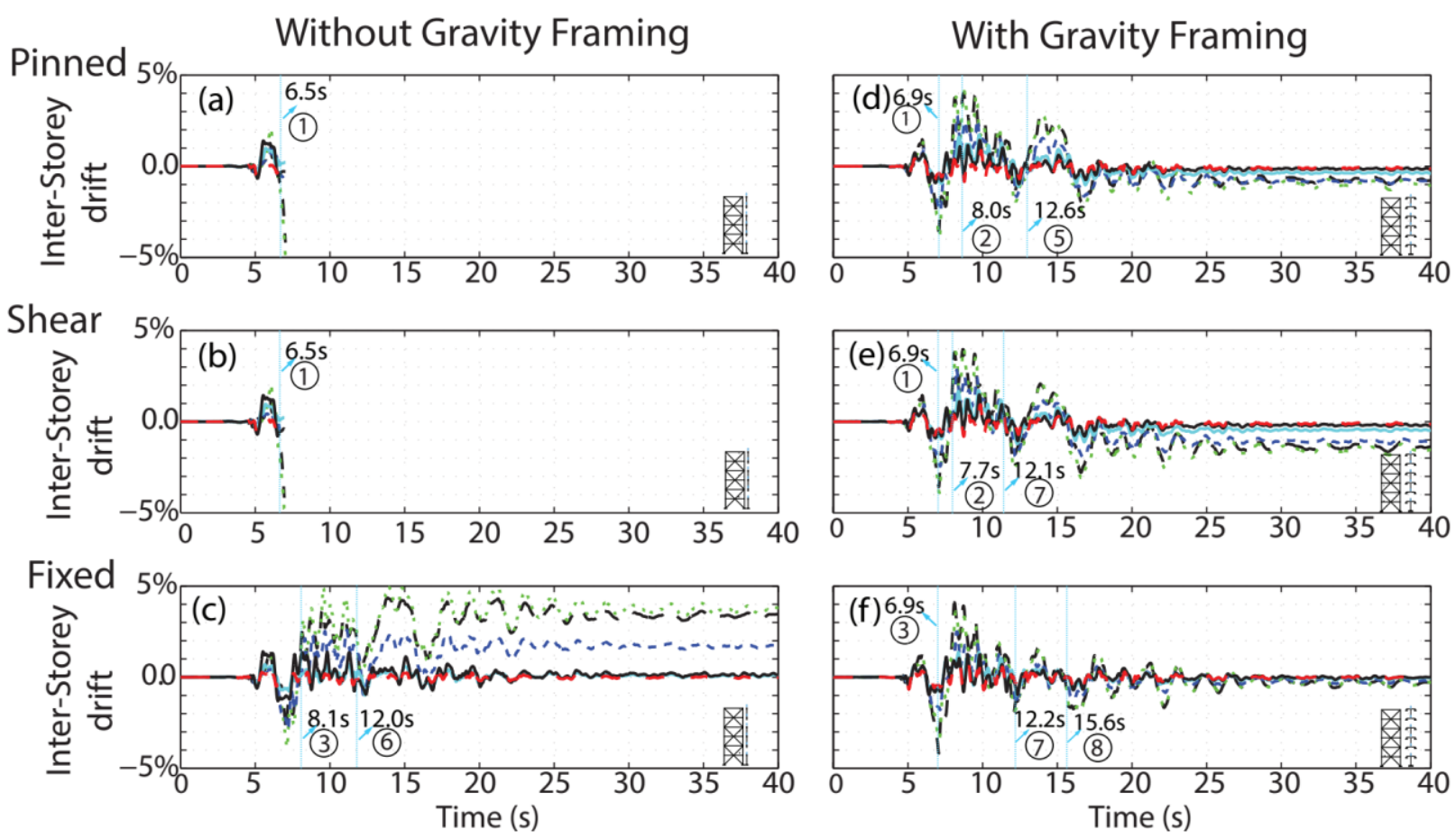

- -Storey1 ....Storey2 - - -Storey3—Storey4 —-Storey5 - . Storey6

Fig. 5. Dynamic response of the 6-storey SCBF for the Nishi-Akashi record from the Kobe 1995 ground motion at a scale factor of 3.8 (1.25MCE)
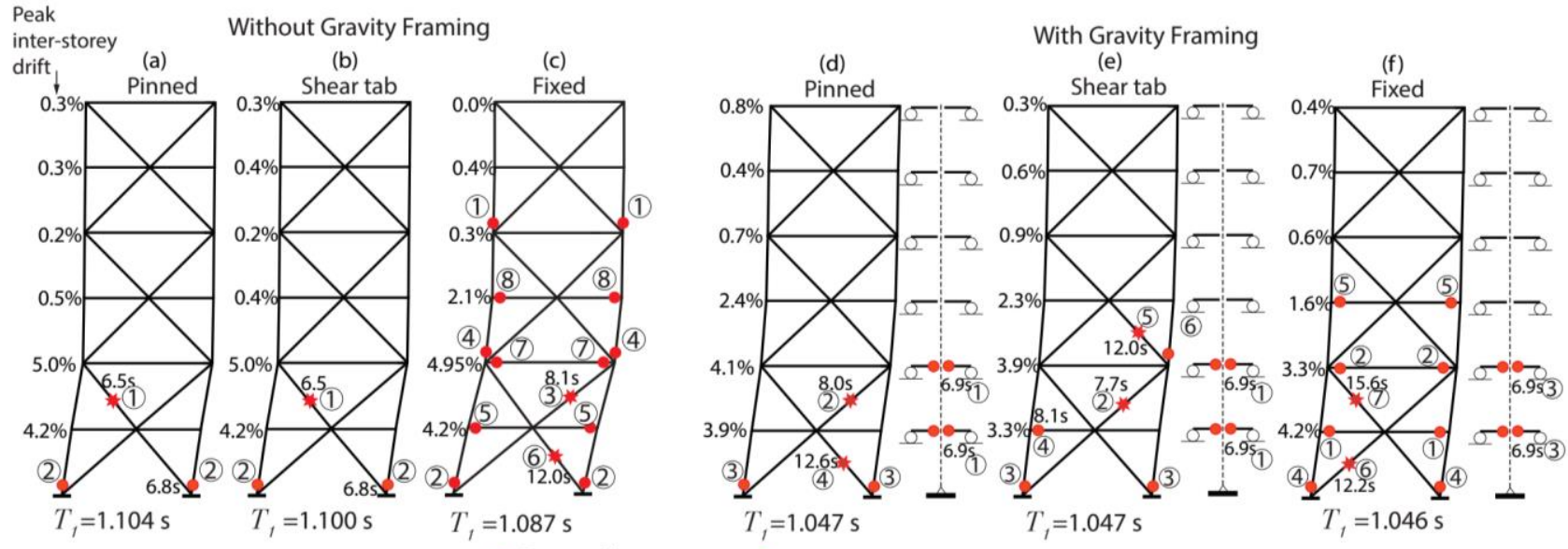

* Brace fracture

-Yielding point

Fig. 6. Sequence of damage during Nishi-Akashi record from the Kobe 1995 ground motion at a scale factor of 3.8

\subsection{Models with gravity framing}

The models described above were also modelled with the additional lateral strength and stiffness of the gravity framing. Figure 5 shows that this enhances the distribution of nonlinearity along the height of the building, reducing both the maximum inter-storey drift and the residual drifts. Figure 6(d) shows the damage progression for a model with pinned connections when the gravity framing is also modelled. Relative to the case without gravity framing, brace fracture is postponed to the next strong cycle in the other direction $(8.0 \mathrm{~s})$. Moreover, after the brace fractures, 
the gravity framing prevents the collapse that was modelled as occurring immediately after brace fracture when gravity framing was not considered. When the connections in the braced bay are instead modelled as shear tabs, the maximum drift reduces by only $5 \%$. The gravity connections in the first two storeys yield at essentially the same time as in the model with pinned connections, and braces fracture at approximately the same times in both models even if it is not the same brace that fractures second.

Somewhat different results are observed in the model with fixed connections. In this model, yielding occurs at several points in gravity connections and in braced bay elements along the height of the building (steps 1 to 6) before the first fracture happens. This illustrates how fixed connections within the braced bay can further redistribute loads after initial brace buckling or yielding, even beyond the level of redistribution that was seen with gravity framing but pinned or shear tab connections. The residual drifts are also smaller for the model with fixed connections than for the other two models. For instance, the maximum residual drift is $0.95 \%$ in the second floor for the model with gravity framing and pinned connections, compared to only $0.37 \%$ in the first floor for the model with fixed connections.

\section{Collapse risk assessment}

In this section, the FEMA P695 [23] methodology is used to evaluate the collapse capacity of each numerical model. According to this methodology, archetype structures with similar seismic behaviour are assembled into performance groups. Each performance group should consist of at least three archetypes, each designed within a selected range of structural geometry and design parameters so as to reflect the major changes in structural behaviour within the archetype design space. The collapse potential of that archetype is then evaluated for each performance group by comparing the calculated adjusted collapse margin ratio (ACMR) to an acceptable ACMR that was determined according to the uncertainty factors of structural system. The ACMR of a single archetype must be greater than the acceptable collapse margin ratio corresponding to a $20 \%$ collapse probability limit ( $\mathrm{ACMR}_{20 \%}$ ) to pass the trial, and the average value of ACMR for all archetypes in the performance group must also meet a $10 \%$ collapse probability limit. The ACMR is computed using the following equation:

$$
A C M R=\frac{\hat{S}_{C T}}{S_{M T}} S S F
$$

where $\hat{S}_{C T}$ is the median collapse intensity computed through nonlinear dynamic analysis, $S_{M T}$ is the MCE ground motion spectral demand, and $S S F$ is the spectral shape factor to account for the frequency content of the ground motion record set. Table 7-3 in FEMA P695 [23] presents the values of ACMR $20 \%$ for different values of total system collapse uncertainty $\left(\beta_{\text {Tor }}\right)$, which includes the record-to-record uncertainty $\left(\beta_{\text {RTR }}\right)$, design requirement robustness $\left(\beta_{D R}\right)$, test data accuracy $\left(\beta_{T D}\right)$ and modelling accuracy $\left(\beta_{M D L}\right)$ :

$$
\beta_{\text {TOT }}=\sqrt{\beta_{R T R}^{2}+\beta_{D R}^{2}+\beta_{T D}^{2}+\beta_{M D L}^{2}}
$$

In this study, the record-to-record uncertainty $\left(\beta_{\text {RTR }}\right)$ values are determined from the multiple stripe analysis results. As in NIST [24], $\beta_{D R}, \beta_{T D}$ and $\beta_{M D L}$ were all assumed to be equal to 0.2 , which represents a quality rating Good (B). The SSF values were determined using Table 7-1 of FEMA P695 [23]. Consider a period based ductility larger than 8 [20], the corresponding $S S F$ factors are 1.33, 1.41 and 1.58 for the three-, six-, and 12-storey models, respectively.

\subsection{Influence of connection fixity on collapse risk without modelling gravity framing}

Fig. 7 shows the collapse fragility curves for the considered models without and with the gravity framing modelled.

The horizontal axis shows $S_{a}\left(T_{1}\right)$, the mean spectral acceleration value of the first mode for the ground motion suite, 
normalized by the MCE ground motion spectral intensity $\left(S_{M T}\right)$, so the collapse margin ratio $\left(\mathrm{CMR}=\hat{S}_{C T} / S_{M T}\right)$ can be taken directly from collapse fragility curves as the $\mathrm{x}$-coordinate associated with a $50 \%$ probability of collapse. When the contribution of the gravity framing is neglected (Figs. 7(a-c)), the difference between the median collapse capacities for models with pinned connections and those for models with shear-tab connections is less than 5\% for all three buildings. Although increasing the connections' strength and stiffness to be fully fixed does not affect the CMR for the 3 -storey building, the median collapse intensity improves by $22 \%$ and $30 \%$ for 6 -storey and 12 -storey buildings, respectively. However, the probability of collapse at the MCE level is still unacceptably high (54\%) for the 12-storey building, even with this improvement in collapse capacity due to fully fixed connections. This probability of collapse is also much higher than the probability computed in a previous study [24] because of the difference in damping models that were used, as will be discussed in Section 6.4.

\subsection{Influence of gravity framing on collapse risk}

The right side of Fig. 7 presents the collapse fragility curves for models that include the gravity framing (i.e. gravity columns and gravity beam-column connections). Compared to the results for models without gravity framing (left side of Fig. 7), a clear improvement is seen in the fragility curves for all modelled SCBFs. Regardless of the connection type within the braced bay, the CMR increases from 1.20 to 1.57 for the three-storey building when the gravity framing is considered relative to models without gravity framing. For the six-storey building, the median collapse capacity increases by $11 \%$ and $33 \%$ for models with fixed connections and shear-tab connections, respectively, when compared to the median collapse capacity of the same frames without modelling the gravity framing. For the 12-storey building, modelling the gravity framing has an even more significant effect on collapse capacity, increasing the CMR by a factor of between 2.5 and 2.7 .

Figs. 7 (d) and (e) indicate that changing the beam-column connections in the braced bay from pinned to fixed has a negligible effect on the median collapse capacity of three- and six-storey buildings when the gravity framing is modelled. This implies that the influence of the flexural reserve capacity of the gravity columns and connections is much more significant than the connections within the braced bay for these buildings. However, there is a significant improvement in collapse capacity with connection fixity in the 12-storey frame, even with gravity framing. For this taller structure, the gravity columns provide less stiffness relative to the braced bay than for the other buildings, and therefore the fixed connections within the braced bay play a greater role in distributing yielding to reduce drift concentration and dissipate energy.

Table 4 summarizes the results of the evaluation process for the models without or with the gravity framing contribution. In this table, the calculated ACMR values are compared to acceptable ACMR $20 \%$ values in FEMA P695 to evaluate the collapse safety of each model of its individual archetype building. All models of the three-storey building satisfy the FEMA P695 criterion, and the collapse capacity improves significantly when the gravity framing is included. The 6-storey model performance is unacceptable for the pinned and shear-tab cases when the gravity framing is not modelled. However, assuming fixed connections improves the collapse capacity to be acceptable, and modelling the gravity framing results in an even greater improvement. In the case of the 12-storey building, systems without the gravity framing modelled all have highly unacceptable performance, but modelling the gravity framing greatly enhances their performance to be acceptable.

Finally, when the gravity framing is modelled, the 12-storey SCBF is the least vulnerable to collapse of the three considered buildings, which is consistent with findings from previous earthquakes and from other studies in which low rise SCBFs have been found more vulnerable [34]. Conversely, the results of models without the gravity framing contribution showed that the 12-storey SCBF has the greatest potential for collapse. 

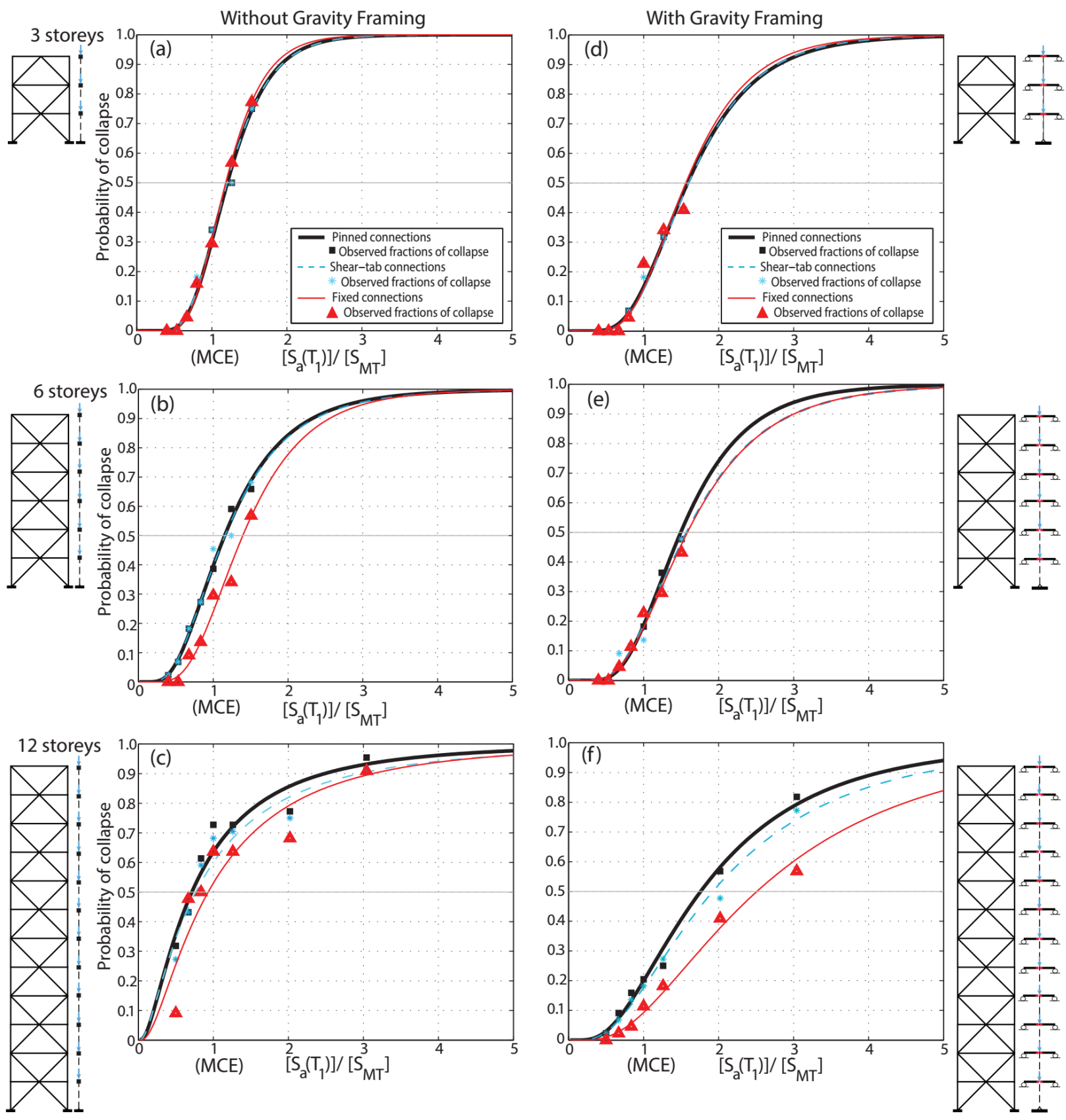

Fig. 7. Collapse fragility curves for three-, six-, and 12-storey SCBF a)without gravity framing contribution b)with gravity framing contribution

\subsection{Influence of gravity columns alone on collapse risk}

As discussed in the previous section, the total contribution of gravity framing can improve the collapse capacity of SCBFs significantly. However, this is typically not considered in current design and analysis because of the difficulty of modelling gravity connections and the lack of information about their expected behaviour [35]. A more practical approach for design may be to consider only the portion of gravity framing contribution that comes from continuous gravity columns, which have also been shown to improve collapse capacity [18]. If the gravity columns have sufficient strength and stiffness, they can provide a positive post-yielding stiffness that improves dynamic stability by 
counteracting P- $\Delta$ effects [36]. The flexural stiffness of gravity columns is mobilized when shear storey drifts become nonuniform after brace buckling and yielding; thus, the relevant flexural stiffness of gravity columns depends on the number and locations of storeys with pronounced brace yielding. As a simplified alternative suitable for routine design, the recommendations proposed in this paper are based on the column stiffness ratio ( $\alpha$ ), which quantifies the ratio of stiffness between all of the continuous gravity columns and the bracing bent [19]:

$$
\alpha=\frac{E I}{k h^{3}}
$$

where $I$ is the total moment of inertia provided by all of the continuous gravity columns at a storey level based on their orientations, $k$ is the total lateral stiffness of braced bays at that level based on the axial stiffness of the braces, and $h$ is the height of the storey. For the considered buildings, the values of $\alpha$ are shown in Table 2. These values are associated with 10.5 gravity columns per braced bay for the three- and six-storey buildings, and 4.25 gravity columns per braced bay for the 12-storey building, with all columns oriented to bend about their strong axes.

In order to evaluate the importance of gravity column stiffness as part of the overall contribution of the gravity framing to collapse capacity, the analyses described above were repeated considering the contribution of gravity columns without gravity framing connections, and also for models with half the total stiffness of gravity columns (i.e. $0.5 \alpha$ ), which corresponds to orienting most gravity columns to bend about their weak axes instead of their strong axes. Fig. 8 shows the fragility curves for both of these cases. In this figure, the fragility curves from Figs. 7(a-c) for pinned and fixed connections without modeling the gravity framing are also presented for comparison. Table 4 summarizes the results of the evaluation process for the models with the contribution of gravity columns. Sections 6.1 and 6.2 showed that the difference between models with pinned and shear tab connections was less than a $5 \%$ change in the median collapse capacities for all models with different heights. Therefore, the results in this section are presented only for models with pinned and fixed connections. The CMR values for these cases (for buildings with different heights) are between the CMR values calculated for cases without and with the gravity framing.

The low-rise (three-storey) building is able to pass the FEMA P695 collapse criterion regardless of the beam-column connection fixity, even without considering the gravity framing contribution.

For the mid-rise (six-storey) building, although cases with pinned or shear-tab connections narrowly failed the FEMA P695 criterion when the gravity framing stiffness was artificially reduced, the results when considering full gravity framing connections (Fig. 7(e)) showed that the beam-column connections within the braced bay have a negligible effect on the collapse fragility. Therefore, it is also recommended that a designer may choose whether to use pinned or fixed connections within the braced bay for mid-rise buildings. This is also consistent with the results presented here with continuous columns and without a modified stiffness $(\alpha \times 1.0)$.

For the taller (12-storey) building, no cases satisfied the FEMA P695 collapse criterion without considering the contribution of gravity framing, suggesting that the stiffness of the gravity framing must always be verified regardless of the beam-column fixity within the braced bay. Considering that failure generally initiated in the eleventh storey when the gravity framing was not modelled (as will be shown in Section 7), the analyses suggest that $\alpha$ must be verified as greater than 0.015 at every storey when the beam-column connections within the braced bay are pinned, or $\alpha>0.008$ at every storey when the beam-column connections within the braced bay are fixed. The gravity framing connections are likely to add a beneficial effect, but this is relatively difficult to consider in design and therefore is neglected in these recommendations. 
Table 4

Collapse results for all SCBF models

\begin{tabular}{|c|c|c|c|c|c|c|c|c|c|}
\hline $\begin{array}{c}\text { Beam- } \\
\text { column } \\
\text { connection }\end{array}$ & $\begin{array}{c}\text { Gravity system } \\
\text { model }\end{array}$ & Damping & $\mathbf{S}_{\mathbf{C T}}$ & $\mathbf{S}_{\mathrm{MT}}$ & CMR & $\beta$ & ACMR & $\begin{array}{c}\text { Accept } \\
\text { ACMR }_{20 \%}\end{array}$ & $\begin{array}{l}\text { Pass/Fail } \\
\text { ratio }\end{array}$ \\
\hline \multicolumn{10}{|l|}{ 3-storey } \\
\hline Pinned & None & Tangent & $1.80 \mathrm{~g}$ & $1.50 \mathrm{~g}$ & 1.20 & 0.36 & 1.60 & 1.52 & 1.05 \\
\hline Shear-tab & None & Tangent & $1.80 \mathrm{~g}$ & $1.50 \mathrm{~g}$ & 1.20 & 0.37 & 1.60 & 1.52 & 1.05 \\
\hline Fixed & None & Tangent & $1.80 \mathrm{~g}$ & $1.50 \mathrm{~g}$ & 1.20 & 0.34 & 1.60 & 1.51 & 1.06 \\
\hline Fixed & None & Initial & $2.00 \mathrm{~g}$ & $1.50 \mathrm{~g}$ & 1.33 & 0.34 & 1.78 & 1.51 & 1.18 \\
\hline Pinned & Framing & Tangent & $2.37 \mathrm{~g}$ & $1.50 \mathrm{~g}$ & 1.58 & 0.44 & 2.10 & 1.6 & 1.31 \\
\hline Shear-tab & Framing & Tangent & $2.37 \mathrm{~g}$ & $1.50 \mathrm{~g}$ & 1.58 & 0.43 & 2.10 & 1.6 & 1.31 \\
\hline Fixed & Framing & Tangent & $2.37 \mathrm{~g}$ & $1.50 \mathrm{~g}$ & 1.58 & 0.44 & 2.10 & 1.6 & 1.31 \\
\hline Pinned & Column $\alpha \times 0.5$ & Tangent & $2.01 \mathrm{~g}$ & $1.50 \mathrm{~g}$ & 1.34 & 0.38 & 1.78 & 1.53 & 1.16 \\
\hline Fixed & Column $\alpha \times 0.5$ & Tangent & $2.08 \mathrm{~g}$ & $1.50 \mathrm{~g}$ & 1.39 & 0.39 & 1.85 & 1.53 & 1.21 \\
\hline Pinned & Column $\alpha \times 1.0$ & Tangent & $1.98 \mathrm{~g}$ & $1.50 \mathrm{~g}$ & 1.32 & 0.37 & 1.76 & 1.53 & 1.15 \\
\hline Fixed & Column $\alpha \times 1.0$ & Tangent & $2.12 \mathrm{~g}$ & $1.50 \mathrm{~g}$ & 1.41 & 0.37 & 1.87 & 1.53 & 1.22 \\
\hline \multicolumn{10}{|l|}{ 6-storey } \\
\hline Pinned & None & Tangent & $0.97 \mathrm{~g}$ & $0.85 \mathrm{~g}$ & 1.15 & 0.54 & 1.61 & 1.73 & 0.93 \\
\hline Shear-tab & None & Tangent & $0.97 \mathrm{~g}$ & $0.85 \mathrm{~g}$ & 1.15 & 0.55 & 1.61 & 1.73 & 0.93 \\
\hline Fixed & None & Tangent & $1.19 \mathrm{~g}$ & $0.85 \mathrm{~g}$ & 1.40 & 0.47 & 1.97 & 1.63 & 1.21 \\
\hline Fixed & None & Initial & $1.55 \mathrm{~g}$ & $0.85 \mathrm{~g}$ & 1.83 & 0.58 & 2.57 & 1.76 & 1.46 \\
\hline Pinned & Framing & Tangent & $1.22 \mathrm{~g}$ & $0.85 \mathrm{~g}$ & 1.43 & 0.45 & 2.02 & 1.62 & 1.25 \\
\hline Shear-tab & Framing & Tangent & $1.33 \mathrm{~g}$ & $0.85 \mathrm{~g}$ & 1.56 & 0.50 & 2.21 & 1.66 & 1.33 \\
\hline Fixed & Framing & Tangent & $1.34 \mathrm{~g}$ & $0.85 \mathrm{~g}$ & 1.58 & 0.50 & 2.22 & 1.66 & 1.34 \\
\hline Pinned & Column $\alpha \times 0.5$ & Tangent & $0.98 \mathrm{~g}$ & $0.85 \mathrm{~g}$ & 1.15 & 0.49 & 1.63 & 1.66 & 0.98 \\
\hline Fixed & Column $\alpha \times 0.5$ & Tangent & $1.19 \mathrm{~g}$ & $0.85 \mathrm{~g}$ & 1.40 & 0.48 & 1.97 & 1.63 & 1.20 \\
\hline Pinned & Column $\alpha \times 1.0$ & Tangent & $1.19 \mathrm{~g}$ & $0.85 \mathrm{~g}$ & 1.41 & 0.58 & 1.99 & 1.76 & 1.13 \\
\hline Fixed & Column $\alpha \times 1.0$ & Tangent & $1.26 \mathrm{~g}$ & $0.85 \mathrm{~g}$ & 1.48 & 0.58 & 2.09 & 1.76 & 1.19 \\
\hline \multicolumn{10}{|l|}{ 12-storey } \\
\hline Pinned & None & Tangent & $0.34 \mathrm{~g}$ & $0.47 \mathrm{~g}$ & 0.72 & 0.97 & 1.14 & 2.22 & 0.51 \\
\hline Shear-tab & None & Tangent & $0.36 \mathrm{~g}$ & $0.47 \mathrm{~g}$ & 0.77 & 0.98 & 1.22 & 2.22 & 0.55 \\
\hline Fixed & None & Tangent & $0.44 \mathrm{~g}$ & $0.47 \mathrm{~g}$ & 0.94 & 0.94 & 1.49 & 2.22 & 0.67 \\
\hline Fixed & None & Initial & $1.34 \mathrm{~g}$ & $0.47 \mathrm{~g}$ & 2.85 & 0.95 & 4.50 & 2.22 & 2.03 \\
\hline Pinned & Framing & Tangent & $0.84 \mathrm{~g}$ & $0.47 \mathrm{~g}$ & 1.79 & 0.67 & 2.83 & 1.84 & 1.54 \\
\hline Shear-tab & Framing & Tangent & $0.90 \mathrm{~g}$ & $0.47 \mathrm{~g}$ & 1.91 & 0.70 & 3.02 & 1.88 & 1.61 \\
\hline Fixed & Framing & Tangent & $1.17 \mathrm{~g}$ & $0.47 \mathrm{~g}$ & 2.50 & 0.69 & 3.95 & 1.88 & 2.10 \\
\hline Pinned & Column $\alpha \times 0.5$ & Tangent & $0.46 \mathrm{~g}$ & $0.47 \mathrm{~g}$ & 0.98 & 0.89 & 1.55 & 2.22 & 0.71 \\
\hline Fixed & Column $\alpha \times 0.5$ & Tangent & $0.66 \mathrm{~g}$ & $0.47 \mathrm{~g}$ & 1.40 & 0.90 & 2.21 & 2.22 & 1.00 \\
\hline Pinned & Column $\alpha \times 1.0$ & Tangent & $0.58 \mathrm{~g}$ & $0.47 \mathrm{~g}$ & 1.23 & 0.66 & 1.94 & 1.88 & 1.04 \\
\hline Fixed & Column $\alpha \times 1.0$ & Tangent & $0.83 \mathrm{~g}$ & $0.47 \mathrm{~g}$ & 1.76 & 0.69 & 2.79 & 1.91 & 1.46 \\
\hline
\end{tabular}



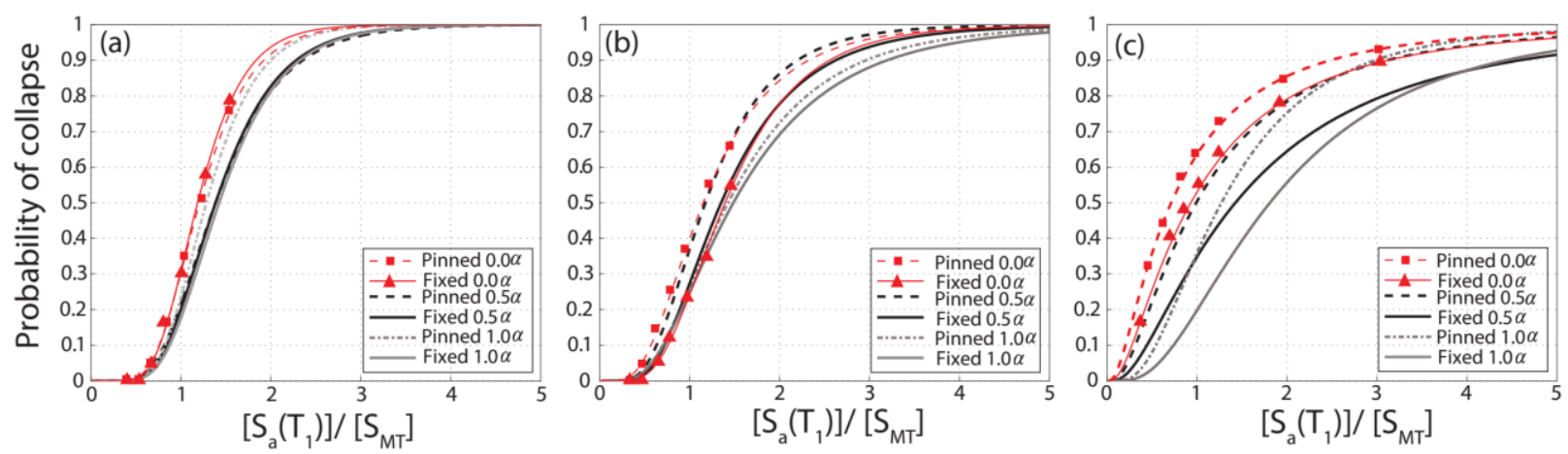

Fig. 8. Collapse fragility curves for a) three-, b) six-, and c) 12-storey SCBF considering only the contribution of gravity columns

\subsection{Influence of damping model on collapse risk}

For all of the models discussed above, the tangent stiffness was used to calculate the stiffness-proportional damping component of the Rayleigh damping matrix and the Rayleigh coefficients. To evaluate the significance of this assumption, the analyses described above were repeated for the models with fixed connections when the gravity framing was not modelled, but using the initial stiffness of all structural elements to compute the damping matrix. These assumptions were based on the modelling approach described in NIST [24]. The CMR for the three-storey model increases by $10 \%$ for the case with initial stiffness-proportional damping compared to the case with tangent stiffness-proportional damping, and the influence on the results becomes more significant as the building height increases. Figs. 9(b) and 9(c) show that the median collapse capacity increases by $30 \%$ and $310 \%$ for the six- and $12-$ storey buildings, respectively. For the 12-storey building, this difference was enough to change the computed ACMR from unacceptable to acceptable. This finding demonstrates the important influence of the inherent damping model on the collapse capacity of SCBFs, and is consistent with previous findings that unrealistic large damping forces can be produced when the Rayleigh damping matrix is computed based on the initial stiffness of CBFs [30].
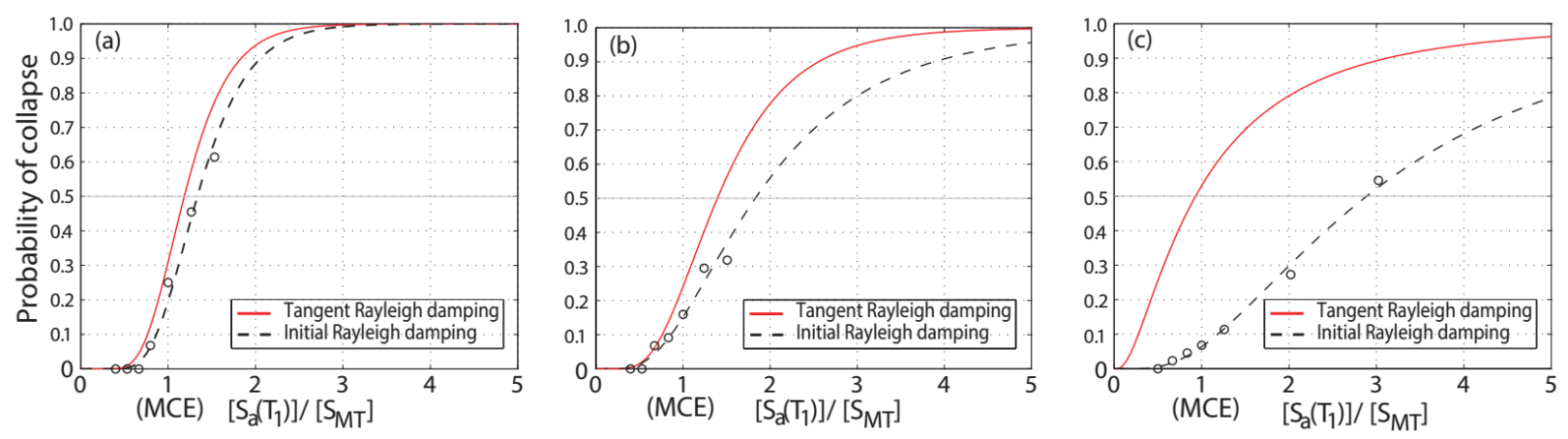

Fig. 9. Collapse fragility curves for a) three-, b) six-, and c) 12-storey SCBF without gravity framing contribution and fixed connections

\section{Inter-storey drift response}

The distribution of inelastic deformation along the height of the building near collapse has often been identified as a concern for braced frames [37]. This section expands on Section 5, which showed an example of how the connection strength and stiffness can change the collapse mechanism of an SCBF, by comparing the median peak inter-storey drift ratios (IDR) of the considered braced frames. Fig. 10 shows the results for the three and six-storey buildings at MCE, $1.25 \times \mathrm{MCE}$ and $1.5 \times \mathrm{MCE}$, and for the 12-storey building at MCE, $1.25 \times \mathrm{MCE}$ and $2 \times \mathrm{MCE}$. For clarity, the results are shown only for models with the gravity framing neglected and for one model including gravity framing. That model was selected to be the case with shear tab connections in the braced bay because this is expected to be most representative of the response with the new replaceable brace module (Fig. 1d), unless a fixed connection is 
designed. The median peak IDR is shown in this figure, as well as the limit on the peak inter-storey drifts at the MCE level from ASCE 7-16 [38]. The collapse limit was set as a 5\% inter-storey drift ratio, so when an individual storey in a given model reached this limit, the analysis was stopped and the model was considered to have collapsed.

For the three-storey model, the median peak IDR at the first storey exceeds the MCE limit, regardless of the connection fixity and the gravity framing modelling. There is only a slight difference between the median peak IDR for models with pinned or shear-tab connections if the gravity framing is not modelled, and assuming fixed connections affects the distribution of peak IDR over the height, even though it does not affect the collapse capacity (Fig. 7(a)).

For six-storey buildings, Fig. 9 shows that the maximum value of median peak IDR occurs in the second floor for all considered models. The median peak IDR response for SCBFs with pinned connections are similar to the median peak IDR response for the models with shear tab connections in models without gravity framing, as was previously seen in the example of Section 5 and in the collapse fragility curves of Fig. 7(b).

For the 12-storey building, Fig. 9 shows that changing the connection fixity has only a slight influence on the median peak IDR response, but adding the gravity framing to the model has a substantial effect. The median peak IDR response for the 12-storey SCBFs without the gravity framing contribution shows that large drifts due to brace damage commonly occur at the $11^{\text {th }}$ storey under MCE and 1.25MCE ground motion levels. At twice the MCE level, more than 50\% of the ground motions caused collapse (see Fig. 7(c) and 7(f)), but the storey that caused collapse was distributed more uniformly over the height, leading to the median peak IDR being less than 5\% at all storeys. When the gravity framing is modelled, the storey that initiates collapse becomes more uniformly distributed. 

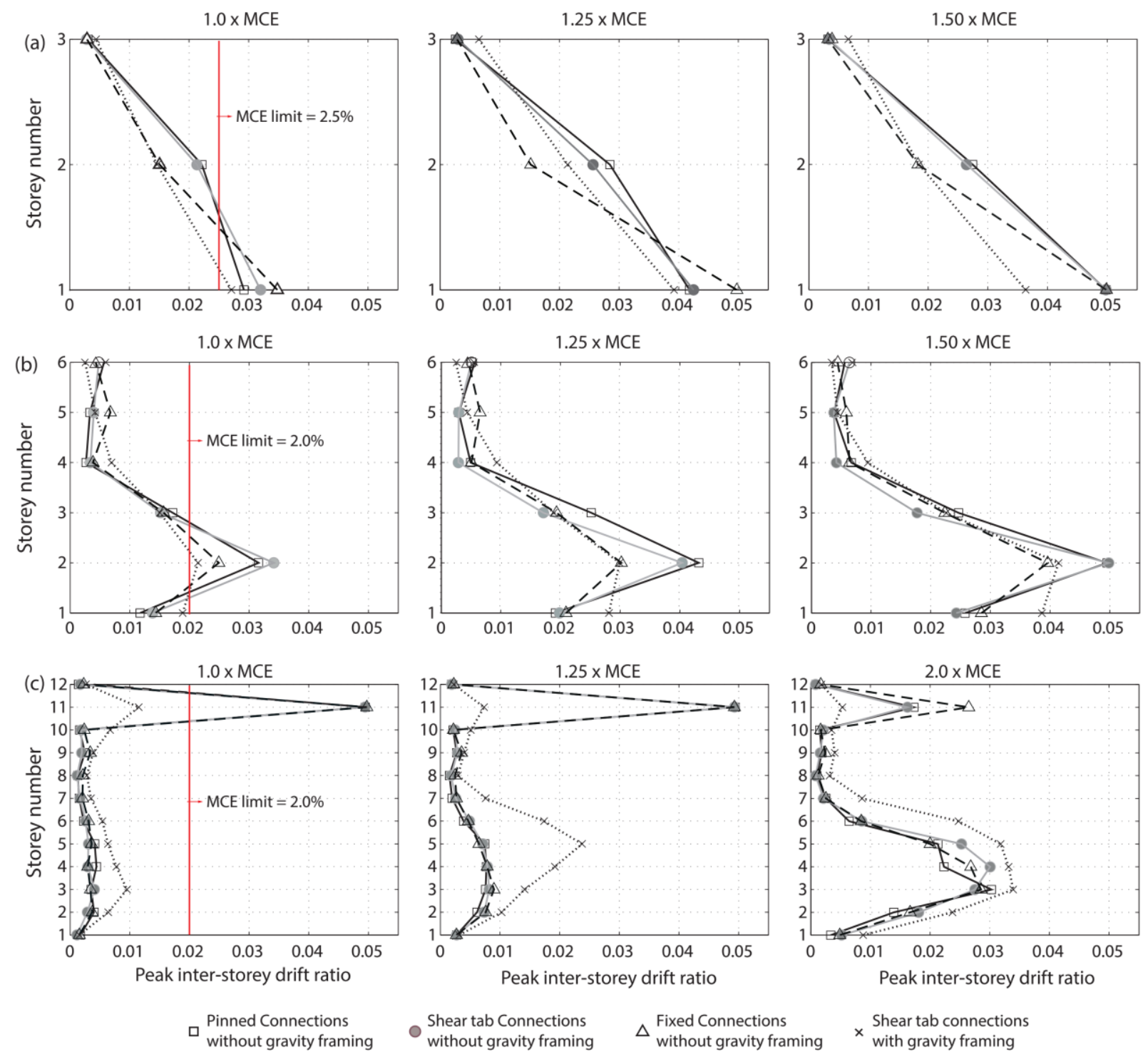

Fig. 10. Peak inter-storey drift ratios for (a) 3-storey building (b) 6-storey building (c) 12-storey building

In order to measure the effects of connection fixity and gravity framing on drift concentration tendency, a drift concentration factor (DCF) was considered, defined as the ratio of maximum storey drift to the maximum roof drift [19]. Values of DCF much greater than unity indicate that drift is not distributed evenly over the building height. DCF index values are shown in Fig. 11 at the MCE intensity level. Fig. 11 indicates that the drift concentration severity increases as the building height increases. Fig. 11(a) shows that providing fixed connections leads to slightly smaller DCF values for the taller frames. The effect of gravity framing on DCF is more significant, especially for the 12storey frame.

DCF values are also presented for models with only the gravity columns contribution in Fig. 10(b). DCF values for these systems are comparable to those calculated for models that include the complete gravity framing (Fig. 11(a)). As expected, increasing the stiffness of continuous gravity columns decreases DCF values. 

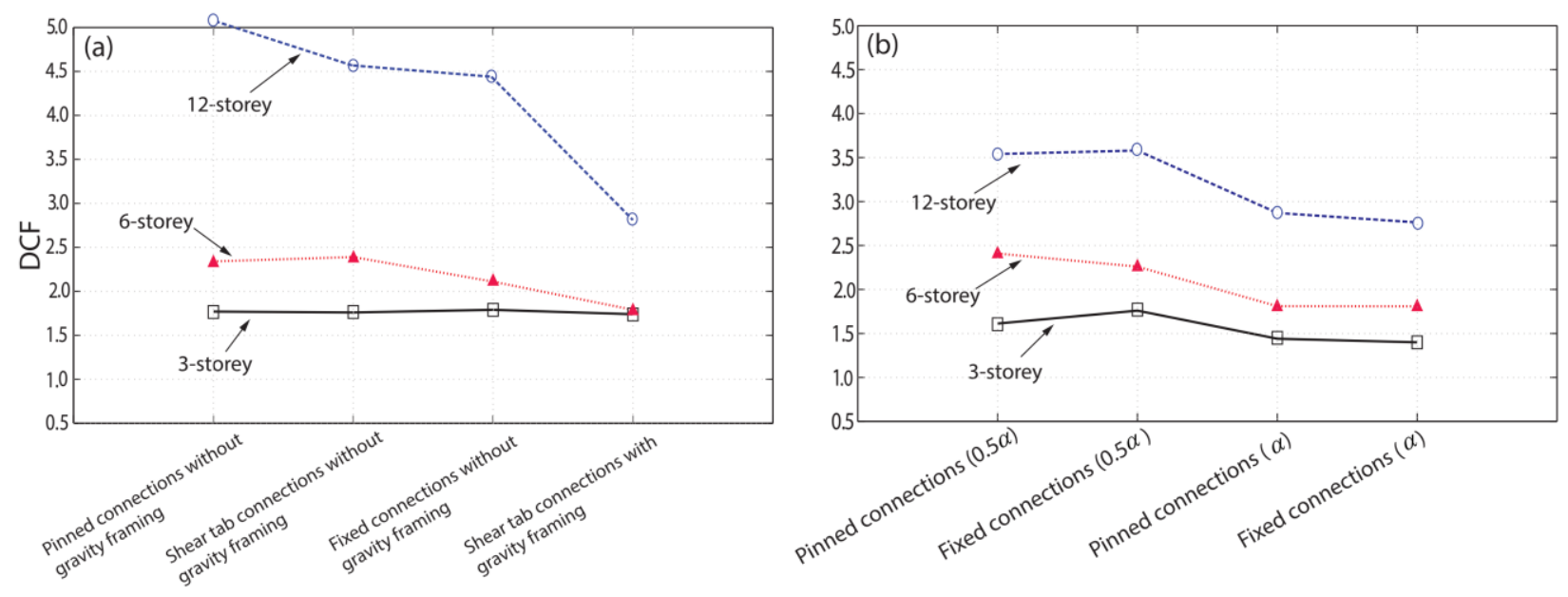

Fig. 11. DCF index values at MCE level for different models considering a) connection fixity and gravity framing effects b) connection fixity and gravity column effects

\section{Summary and design recommendations}

This paper investigated the influence of connection fixity on the collapse capacity of SCBFs, without or with the gravity framing in the numerical model. Three-, six- and twelve-storey SCBF buildings were considered, with three different connection conditions (i.e. pinned, shear tab and fixed) at the beam-column connections. The collapse fragility curves were constructed using multiple stripe analysis. Tangent stiffness proportional Rayleigh damping was used, except that one model for each building was also analyzed using the initial stiffness to compute the damping matrix and Raleigh damping coefficients. The main findings are:

- The difference between models with pinned and shear tab connections was less than a 5\% change in the median collapse capacities for all buildings. When the contribution of the gravity framing was ignored, the connection fixity had essentially no effect on the collapse capacity for the three-storey SCBF, but assuming fixed connections improved the collapse margin ratio by $22 \%$ and $33 \%$ for six- and 12 -storey SCBFs, respectively, relative to a model with pinned connections.

- Modelling gravity framing improved the collapse capacity of the SCBF buildings significantly. Indeed, the influence of gravity framing in the three- and six-storey buildings was so strong that the connection fixity within the braced bay had no influence on the collapse capacity of the system when gravity framing was modelled. For the 12-storey building, modelling the gravity framing increased the collapse margin ratio to be 2.5 times larger on average than for the models without the gravity framing.

- The stiffness matrix used to compute the Rayleigh damping had a significant effect on the collapse margin ratio, particularly in taller buildings. Using the initial stiffness instead of the tangent stiffness increased the collapse margin ratio by $10 \%, 30 \%$ and $310 \%$ for three-, six-, and twelve-storey buildings, respectively.

- The modelled connection fixity could also change the plastic failure mechanism near collapse. Assuming fixed connections caused more consistent median inter-storey drift ratios over the height. Modeling gravity framing also changed the plastic mechanism by reducing the peak inter-storey drift ratios, and improving the distribution of nonlinearity along the height of the building.

- For low-rise and mid-rise buildings (up to six storeys), there is no need to provide beam-column fixity within the braced bay because its effect is negligible when compared to that of typical gravity framing. However, for taller buildings (12 storeys), the gravity framing was found to be essential for ensuring an adequate collapse margin ratio, with additional stiffness required when the connections within the braced bay are pinned compared to when they are fixed. A check on minimum gravity column stiffness of $\alpha>0.015$ is recommended when the connections within the braced bay are fixed, or $\alpha>0.008$ when they are designed as fixed. 
Based on these findings, gravity framing has a strong influence on the collapse capacity of special concentrically braced frames and it should be considered in collapse modelling of these type of buildings. When sufficient gravity framing is provided to redistribute loads after the onset of brace nonlinearity, as described above, no additional design requirements are needed for the connection fixity within the braced bay.

While the primary objective of this paper was to compare the response of special concentrically braced frames with different degrees of beam-column connection fixity, the results that were based on a $20 \%$ probability of collapse for individual archetypes would not be considered acceptable based on a $10 \%$ probability of collapse for performance groups. Therefore, they point to a need for further study of the collapse performance of concentrically braced frames, with due consideration of such modelling parameters as gravity framing, inherent damping modeling, panel zone deformations, composite action if present, and beam and column deterioration at drift levels near collapse.

\section{References}

[1] Astaneh-Asl A. Seismic behaviour and design of gusset plates. Steel TIPS, Structural Steel Educational Council, Moraga, California, December: 1998.

[2] Lehman DE, Roeder CW, Herman D, Johnson S, Kotulka B. Improved seismic performance of gusset plate connections. J Struct Eng 2008;134:890-901. doi:10.1061/(ASCE)0733-9445(2008)134:6(890).

[3] Roeder CW, Lumpkin EJ, Lehman DE. A balanced design procedure for special concentrically braced frame connections. J Constr Steel Res 2011;67:1760-72. doi:10.1016/j.jcsr.2011.04.016.

[4] Tsai C-Y, Tsai K-C, Lin C-H, Wei C-Y, Wang K-J, Yu Y-J, et al. Cyclic responses of three 2-storey seismic concentrically braced frames. Front Arch Civ Eng China 2010;4:287-301. doi:10.1007/s11709-010-0087-1.

[5] Lumpkin EJ. Enhanced seismic performance of multi-storey special concentrically brace frames using a balanced design procedure. MSc thesis, University of Washington, 2009.

[6] Stevens D, Wiebe L. Large-scale testing of a replaceable connection for concentrically braced frames. 16th World Conf. Earthq. Eng., Santiago Chile, January 9th to 13th: 2017.

[7] Yoo JH, Lehman DE, Roeder CW. Influence of connection design parameters on the seismic performance of braced frames. J Constr Steel Res 2008;64:607-23. doi:10.1016/j.jcsr.2007.11.005.

[8] Stoakes CD, Fahnestock LA. Cyclic flexural testing of concentrically braced frame beam-column connections. J Struct Eng 2011;137:739-47. doi:10.1061/(ASCE)ST.1943-541X.0000326.

[9] Stoakes CD, Fahnestock LA. Cyclic flexural analysis and behaviour of beam-column connections with gusset plates. J Constr Steel Res 2012;72:227-39. doi:10.1016/j.jcsr.2011.12.008.

[10] Uriz P, Mahin SA. Toward earthquake-resistant design of concentrically braced steel-frame structures. UCB/PEER-2008/08, Univ. of California, Berkeley, CA.: 2008.

[11] Bradley CR, Fahnestock LA, Hines EM, Sizemore JG. Full-scale cyclic testing of low-ductility concentrically braced frames. J Struct Eng 2017;143:04017029. doi:10.1061/(ASCE)ST.1943541X.0001760.

[12] Sizemore JG, Fahnestock LA, Hines EM, Bradley CR. Parametric Study of Low-Ductility Concentrically Braced Frames under Cyclic Static Loading. J Struct Eng 2017;143:04017032. doi:10.1061/(ASCE)ST.1943-541X.0001761.

[13] Kanyilmaz A. Secondary frame action in concentrically braced frames designed for moderate seismicity: a full scale experimental study. Bull Earthq Eng 2016;15:2101-27. doi:10.1007/s10518-016-0054-x.

[14] Malaga-Chuquitaype C, Elghazouli AY. Contribution of secondary systems to the seismic performance of steel framed structures. 14th Eur. Conf. Earthq. Eng., Ohrid, Republic of Macedonia: 2010. 
[15] Liu J, Astaneh-Asl A. Cyclic testing of simple connections including effects of slab. J Struct Eng 2000;126:32-9.

[16] Liu J, Astaneh-Asl A. Moment-rotation parameters for composite shear tab connections. J Struct Eng 2004;130:1371-80. doi:10.1061/(ASCE)0733-9445(2004)130:9(1371).

[17] Green TP, Leon RT, Rassati GA. Bidirectional tests on partially restrained, composite beam-to-column connections. J Struct Eng 2004;130:320-7.

[18] Ji X, Kato M, Wang T, Hitaka T, Nakashima M. Effect of gravity columns on mitigation of drift concentration for braced frames. J Constr Steel Res 2009;65:2148-56. doi:10.1016/j.jcsr.2009.07.003.

[19] MacRae GA, Kimura Y, Roeder C. Effect of column stiffness on braced frame seismic behaviour. J Struct Eng 2004;130:381-91.

[20] Hsiao P-C, Lehman DE, Roeder CW. Evaluation of the response modification coefficient and collapse potential of special concentrically braced frames. Earthq Eng Struct Dyn 2013;44:657-75. doi:10.1002/eqe. 2286 .

[21] Málaga-Chuquitaype C, Elghazouli AY, Enache R. Contribution of secondary frames to the mitigation of collapse in steel buildings subjected to extreme loads. Struct Infrastruct Eng 2016;12:45-60. doi:10.1080/15732479.2014.994534.

[22] Hwang S-H, Lignos D. Effect of modeling assumptions on the earthquake-induced losses and collapse risk of steel-frame buildings with special concentrically braced frames. J Struct Eng 2017;143:04017116. doi:10.1061/(ASCE)ST.1943-541X.0001851.

[23] FEMA P695. Quantification of building seismic performance factors FEMA P695. Federal Emergency Management Agency, Washington, D.C.: 2009.

[24] NEHRP Consultants Joint Venture. Evaluation of the FEMA P-695 Methodology for Quantification of Building Seismic Performance Factors (NIST GCR 10-917-8). 2010.

[25] American Society of Civil Engineers (ASCE). Minimum design loads for buildings and other structures (ASCE/SEI 7-05). Reston, Virginia: 2006. doi:10.1061/9780784412916.

[26] American Institute of Steel Construction. Seismic Provisions for Structural Steel Buildings, ANSI/AISC 341-05. Chicago, IL: 2005.

[27] McKenna FT. Object-oriented finite element programming: Frameworks for analysis, algorithms and parallel computing. Ph.D. University of California, CA, 1997.

[28] Newell J, Uang C. Cyclic behavior of steel columns with combined high axial load and drift demand. Rep. No. SSRP-06/22, Dept. of Structural Engineering, University of California, San Diego: 2006.

[29] Gunnarsson IR. Numerical performance evaluation of braced frame systems. MSc thesis, University of Washington, 2004.

[30] Karamanci E, Lignos D. Computational approach for collapse assessment of concentrically braced frames in seismic regions. J Struct Eng 2014;140:1-15. doi:10.1061/(ASCE)ST.1943-541X.0001011.

[31] Hsiao PC, Lehman DE, Roeder CW. Improved analytical model for special concentrically braced frames. J Constr Steel Res 2012;73:80-94. doi:10.1016/j.jcsr.2012.01.010.

[32] Elkady A, Lignos DG. Effect of gravity framing on the overstrength and collapse capacity of steel frame buildings with perimeter special moment frame. Earthq Eng Struct Dyn 2015;44:1289-307. doi:10.1002/eqe. 2519 .

[33] Jalayer F. Direct probabilistic seismic analysis: implementing non-linear dynamic assessments. Doctoral dissertation, Stanford University, 2003.

[34] Chen C-H, Mahin SA. Seismic collapse performance of concentrically steel braced frames. Proc. Struct. 
Congr. 19th Anal. Comput. Spec. Conf., Orlando, Florida: 2010, p. 1-8.

[35] Flores F, Charney F, Lopez-Garcia D. The influence of gravity column continuity on the seismic performance of special steel moment frame structures. J Constr Steel Res 2016;118:217-30. doi:10.1016/j.jcsr.2015.11.010.

[36] Tremblay R. An inverted V-braced frame system exhibiting bilinear response for seismic stability under long duration subduction earthquakes. 9th Int. Conf. Behav. Steel Struct. Seism. Areas, Christchurch, New Zealand: 2018.

[37] Roeder CW, Lehman DE, Clark K, Powell J, Yoo J-H, Tsai K-C, et al. Influence of gusset plate connections and braces on the seismic performance of X-braced frames. Earthq Eng Struct Dyn 2011;40:355-74. doi:10.1002/eqe.1024.

[38] American Society of Civil Engineers (ASCE). Minimum Design Loads and Associated Criteria for Buildings and Other Structures. Reston, Virginia: 2017. doi:10.1061/9780784414248. 